\title{
Current Issues of Mobile Cranes Unification
}

\author{
Batraz Kaytukov ${ }^{1, *}$ and Michail Stepanov ${ }^{1}$ \\ ${ }^{1}$ Moscow State University of Civil Engineering, Yaroslavskoe shosse, 26, Moscow, 129337, Russia
}

\begin{abstract}
The issue of unification of key parts of mobile cranes unification is under study. An explicit comparative analysis of the state of production of mobile cranes in Russia and abroad was carried out. The unit-modular method of completing of crane mechanisms is offered. Creation of efficient unified planetary modular gear trains for mobile
\end{abstract}

\section{Introduction}

Mobile cranes came into common use during assembly works and handling operations in Russia and abroad $[1,2]$.

Depending on the traveling gear, cranes fall into one of the following categories: mobile cranes, rail cranes, wheel-mounted cranes, tracked cranes, truck crane, RT cranes. Mobile cranes, herein after referred to as mobile cranes, have excellent maneuverability and ease of control, which makes it possible to use them for facilities located in diverse places and in tight working space of the cities. Analysis of the design, range and production output of mobile cranes in Russia and abroad showed that over 25 years since 1990, domestic plants have produced about 100 thousand cranes.

\section{Methods}

Mobile cranes basically consist of the following assembly units and components: rotary platform on which a telescopic boom, working gears, gantries and cabin, rotation crown and travel device are mounted [3,4]. When unifying the design of mobile cranes, it is considered that the less key parts are used in the design, the more efficient, easy and cheap their production and use can be, which is important for domestic cranes.

Mobile cranes use as a base chassis: GAZ, MAZ, KamAZ, URAL. The cranes are equipped with: hydraulic drive, telescopic booms with hydraulic cylinders. A frame with supports and rotation crown are used in the construction of the travel device. The operation of the crane mechanisms is carried out by hydraulic drive with the help of hydraulic motors and pumps, which allows to make a stepless change of the operation speed, progressive braking and smooth acceleration.

Lifting and lowering of loads is carried out by a hoisting winch, mounted on the revolving frame. Load winches consist of: Hydraulic motor, brakes, gear box and drum. As a gear box, domestic-made cranes, for example, often use a two-stage cylindrical gearbox

\footnotetext{
* Corresponding author: masmias@ mail.ru
} 
in winches, very rarely a planetary drive, and in foreign cranes planetary reducer is mainly used. Pumps with a volume of 56 and $112 \mathrm{~cm}^{3}$ are used as axial-piston pumps, pressure of 20-32 MPa. A fixed hydraulic motor with a volume of $56 \mathrm{~cm}^{3}$ is used as hydraulic motors of the slewing mechanisms, pressure $20-32 \mathrm{MPa}$. Comparing the characteristics of pumps and hydraulic motors with analogues from abroad, we noticed a lag in the technical level of pumps. Thus the pressure in foreign hydraulic systems is $50 \mathrm{MPa}$ or more.

The table shows the technical specification of some home-produced mobile cranes, depending on their loading capacity.

Table 1. Technical Specifications of Cranes

\begin{tabular}{|l|c|c|c|c|c|c|c|}
\hline Indexes Brand & BC - 3562 & BC - 3577 & BC - 35714 & BC - 45717 & BC - 5576 & BC - 6574 & BC - 6467 \\
\hline Load capacity, t: & 10 & 12,5 & 16 & 25 & & 40 & 50 \\
\hline Boom Length, m & $10-18$ & $8-14$ & $8-18$ & 21 & 30,7 & $10,6-30,34$ & 34 \\
\hline $\begin{array}{l}\text { Operating } \\
\text { Radius, m: } \\
\text { minimum, } \\
\text { maximum }\end{array}$ & $4-9,7$ & $2,8-7,1$ & $1,9-17$ & $1,9-17$ & $3-20$ & $3-28$ & 25 \\
\hline $\begin{array}{l}\text { Hoisting } \\
\text { height, m } \\
\text { under small } \\
\text { operating } \\
\text { radius, under } \\
\text { maximum radius }\end{array}$ & $13,4-18$ & $9-20,5$ & $8-25$ & $10-21,3$ & $10,5-31,3$ & $10,5-30,3$ & 48,6 \\
\hline $\begin{array}{l}\text { Chassis Brand } \\
5,8\end{array}$ & $\begin{array}{c}\text { MAZ } \\
\text { GAZ }\end{array}$ & MAZ & KamAZ & KamAZ & KamAZ & MZKT & MZKT \\
\hline
\end{tabular}

These are main and key parameters of mobile cranes: hoisting capacity, hoisting height, operating radius, boom length.

Domestic industry manufactures mobile cranes with a hoisting capacity, $t: 6,3 ; 10 ; 12,5$; $14 ; 16 ; 20 ; 25 ; 32 ; 40 ; 50$ and 70 , and abroad, in addition to this row, there is a tendency to heavy lift capability, even up to 1,000 tons. Fig. 1 shows a curve showing the output of mobile cranes in terms of load capacity in percent.

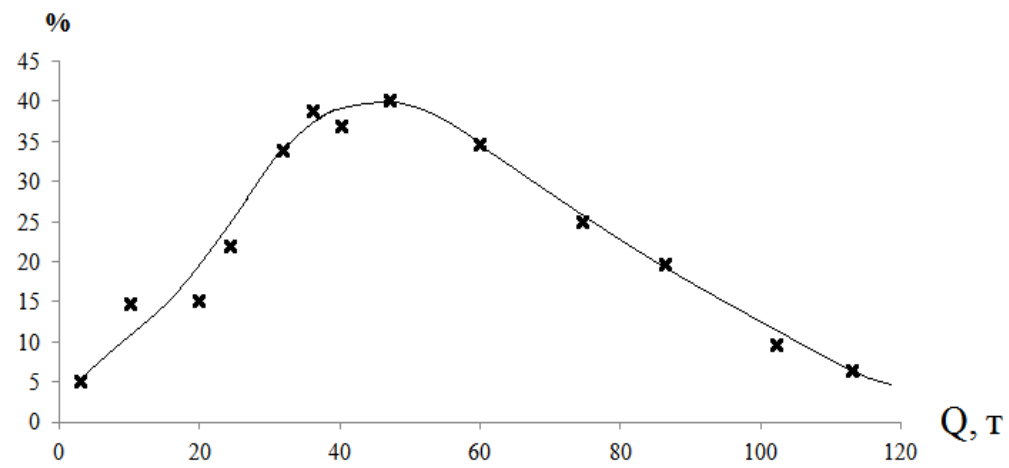

Fig. 1. Mobile cranes output, depending on the hoisting capacity in percent 
The hoisting capacity of top requested mobile cranes in Russia, $t: 16,20,25$ and 32 . The analysis of their design showed that the design activity led to a variety of layouts and configuration of crane mechanisms. The motto of the foreign companies for the production of new cranes is "The fewer elements and basic mechanisms used in the design, the easier and cheaper the production of cranes."

Unification in engineering is bringing different types of products and means of production to a minimum of standard sizes, grades and designs. Unification based on the method of modular mechanisms is an important condition for efficient production and operation of cranes that determine consumer performance. The quality of the components of the crane and technical solutions determine its technical level, which is unattainable without reasonable unification.

Famous companies such as Grove, USA, Coles, England, Kato, Japan, and Liebherr, Germany, have long since adopted a unification of the basic elements for broad cooperation in the design and manufacture of cranes. Faun, Germany, and Tadano, Japan, have good professional practice for the production of components and cranes based on unification. With assistance from Hellmuk, Germany, companies: PPM, France, Rigo, Italy, and Luna, Spain, began installing rotary platforms on the chassis of trucks. Crane manufacturers: Liebherr, Grove, Coles, Kato install planetary slewing gears and winches, characterized by compactness, low weight and reliability.

A multiple planetary gear is installed in the rope drum, powered by a hydraulic motor. What is more Germatich planetary module, Canada is installed as a reduction train in the slewing mechanism. Such design of slewing mechanisms and planetary hoisting winches in the crane are used by many companies. The kinematic scheme, for example, of a planetary winch with a hydraulic drive Liebherr, Germany, is shown in Fig. 2.

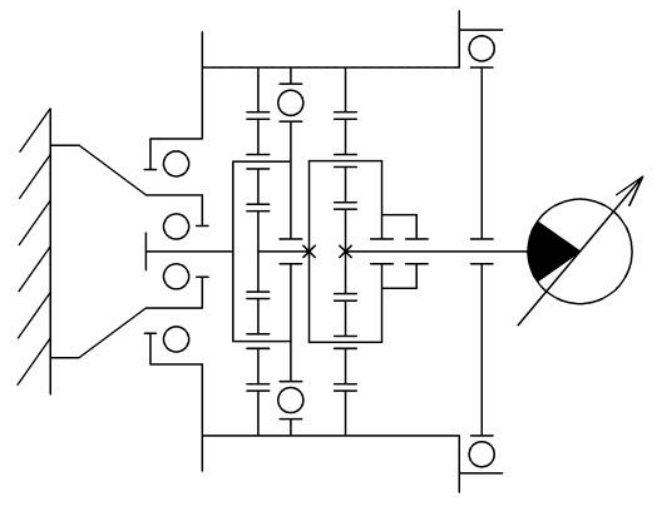

Fig. 2. Kinematic scheme of the planetary hoisting winch

Analysis of the state of production of mobile cranes of various hoisting capacity in Russia and abroad showed that the design activity is aimed at increasing the hoisting capacity and at unification of the technical level of the cranes. As for the quality of the components used in cranes, Russia is lagging behind, which can be corrected within short time frames, by wide unification of the designs of basic elements with the best foreign models, followed by the organization of a specialized issue or obtaining them for cooperation, while the decision is made on the basis of economic calculations. First of all slewing gears and hoisting winches of mobile cranes can be unified [5, 6, 7].

They can be installed on the best home-made base chassis, increasing the technical level and the reliability of the component parts of the cranes. Ivanovo plant uses planetary gears in mobile cranes with a hoisting capacity of 32 tons, but this is an isolated case. In order to 
restore crane production in Russia, a special program shall be developed, like Liebherr, Germany for telescopic cranes.

Russia has experience in development of some modular mechanisms of mobile cranes. To improve the technical level of the cranes, improving the reliability of the rotation mechanism and the truck winch is possible if to develop their design and standardized modular actuator basis of planetary modules. The module is the main technologically complex and time-consuming gear part of the mechanism of the rotation drive and winch. In the development of unified mechanisms of rotation and cargo winch cranes, the task is formed so as to create mechanisms covering a small number of standard sizes of modules of all drives of cranes. The use of a planetary drive reduces overall dimensions, weight characteristics and provides the required load parameters $[8,9]$.

Planetary modular slewing gears and hoisting winches can be developed, for example, for the crane BC-5575, working together with Liebherr. A kinematic scheme of the slewing gear and hoisting winch can be used for the crane BC-5575, with a hoisting capacity of 32 tons $[9,10]$.

For example, for slewing gear with two stages of a planetary modular slewing gear and cylindrical gear with internal gearing and a hydraulic motor. It is known that the gear ratio of the reducer $U=94$, which provides an optimal mode of the frame turning. As a first stage, according to torque, selected planetary module with $\mathrm{r}=80 \mathrm{~mm}, b_{w}=48 \mathrm{~mm}, U=8.5$, where $r$ - planet gear radius, and second stage - module with a radius $r=112 \mathrm{~mm}$, but with a gear face $b_{w}=60 \mathrm{~mm}$ ) [4]. Load performance is provided by strength calculation, selection of materials and dimensions of planetary gear elements .

\section{Conclusion}

When creating competitive unified mobile cranes, the offered method allows to significantly increase the technical level of individual components of the crane, to speed up the design work, to reduce the labor coefficient of calculations and preparation of the design documentation for cranes. For production, this makes it possible to reduce the cost of manufacturing a complex toothed part of the planetary module and mechanisms in general, by increasing the output of mechanisms with the same dimensions, to mitigate the need for processing equipment and to increase the output of different types of mobile cranes at specialized plants. It is possible to build more complex and with different number of storeys houses, to reduce the costs of maintenance and repair of cranes during operation by increasing the reliability of machinery and mobile cranes.

\section{Reference}

1. R. R. Sharapov, A. A. Mamedov, M. A. Stepanov, E. V. Kharlamov, Con. Mec. 77, 5 (2016)

2. R. R. Sharapov, A. A. Mamedov, E. V. Kharlamov, I. G. Bragin, V. V. Klochkov, JBSTU 3 (2016)

3. R.R. Sharapov, P.D. Kapyrin S.Y. Lozovaya, V.V. Yadykina, A.M. Agarkov, MATEC Web of Conferences 5. 03007. (2016)

4. R. R.Sharapov, A. A. Mamedov, E. V. Kharlamov, JBSTU. 6 (2015)

5. R. R. Sharapov, B. A. Kaytukov, M. A.Stepanov, Con. mec. 78, 7 (2017)

6. L.N. Reshetov, Rational Mechanisms Design. (1972)

7. V. I. Telichenko, R. R. Sharapov, M.A. Stepanov, E. V. Kharlamov, SR 22 (2016) 
8. V. N. Kudryavtsev, Yu. N. Kirdyashev, Reference book. (1977)

9. Statutory document RD 22 - 25.180 - 87. Modular gears. ( 1987)

10. A. Birger, B. F. Shorr, G. B. Iosilevich, Reference book. (1979) 